\title{
Fargosides A-E, Triterpenoid Saponins from Holboellia fargesii
}

\author{
Hongzheng Fu, ${ }^{*, a, b}$ Kazuo KoIKe, ${ }^{a}$ Quan Zheng, ${ }^{a}$ Katsuyoshi MitsunAGA, ${ }^{a}$ Zhonghua JiA, ${ }^{a}$ \\ Tamotsu NiKaIdo, ${ }^{*}, a$ Wenhan Lin, ${ }^{b}$ Dean GuO, ${ }^{b}$ and Lihe ZHANG ${ }^{b}$ \\ Department of Pharmacognosy, School of Pharmaceutical Sciences, Toho University, ${ }^{a}$ 2-2-1 Miyama, Funabashi, Chiba \\ 274-8510, Japan and National Laboratory of Natural and Biomimetic Drugs, Peking University, Beijing 100083, People's \\ Republic of China. Received March 12, 2001; accepted May 1, 2001
}

Five new triterpenoid saponins, fargosides A, B, C, D, and E, were isolated from the roots of Holboellia fargesii. The structures of fargosides $A-E$ were elucidated on the basis of chemical and physicochemical evidence and found to be $3 \beta, 20 \alpha$-dihydroxy-29-norolean-12-en-28-oic acid 3- $O$ - $\beta$-D-xylopyranosyl-(1 $\rightarrow 2)$ - $\beta$-D-glucopyranoside (1), 3 $\beta, 20 \alpha, 24$-trihydroxy-29-norolean-12-en-28-oic acid 23- $O$ - $\beta$-D-fucopyranosyl-(1 $\rightarrow 2)$-[ $\alpha$-L-arabinopyranosyl-(1 $\rightarrow 3)]$ - $\beta$-D-glucopyranoside $(2), 3 \beta, 23$-dihydroxy-30-norolean-2,20(29)-dien-28-oic acid 3-O- $\alpha$-L-arabinopyranosyl-(1 $\rightarrow 2)$-[ $\beta$-D-glucopyranosyluronic acid- $(1 \rightarrow 3)]-\alpha$-L-arabinopyranoside $(3), 3 \beta, 23$-dihydroxy-30norolean-12,20(29)-dien-28-oic acid 3- $O$-methyl $\beta$-D-glucopyranosyluronate-(1 $\rightarrow 3)$ - $\alpha$-L-arabinopyranoside (4), and $3 \beta$,23-dihydroxy-olean-12-en-28-oic acid 3- $O$-methyl $\beta$-D-glucopyranosyluronate- $(1 \rightarrow 3)$ - $\alpha$-L-arabinopyranoside (5), respectively.

Key words Holboellia fargesii; Lardizabalaceae; triterpenoid saponin

The medicinal plant Holboellia fargesii ReAub. (Lardizabalaceae) is a tree which grows in the southwest region of the People's Republic of China. Its stems, roots, and fruits have been used as folk medicine for the treatment of cough, lumbago, nephritis and abdominal hernia in Yunnan Province. ${ }^{1,2}$ ) However, there has been no previous chemical study of this plant. Preliminary evaluation indicated that $H$. fargesii contains saponins. The potential medicinal importance and our continuing interest in the chemistry of saponins prompted us to initiate a chemical investigation of this plant. In this paper, we report the isolation and structure elucidation of five new triterpenoid saponins $(\mathbf{1}-\mathbf{5})$ from the roots of this species.

\section{Results and Discussion}

An ethanolic extract of roots of $H$. fargesii was suspended in water and then partitioned successively with EtOAc and $n$ $\mathrm{BuOH}$. The $n$-BuOH soluble fraction, on chromatographic purification over Diaion HP-20 resin, followed by repeated medium-pressure liquid chromatography (MPLC) and HPLC purification, gave five new triterpenoid saponins, termed fargosides $\mathrm{A}-\mathrm{E}(\mathbf{1}-\mathbf{5})$.

Fargoside A (1) gave quasi-molecular ions at $\mathrm{m} / \mathrm{z} 775$ $[\mathrm{M}+\mathrm{Na}]^{+}$and $791[\mathrm{M}+\mathrm{K}]^{+}$by matrix-assisted laser desorption ionization time-of-flight (MALDI-TOF) MS. The molecular formula of $\mathrm{C}_{40} \mathrm{H}_{64} \mathrm{O}_{13}$ was confirmed by high resolution (HR)-FAB-MS. The IR spectrum of 1 showed an absorption bond for a carbonyl group at $1685 \mathrm{~cm}^{-1}$. The ${ }^{13} \mathrm{C}$-NMR spectrum showed 40 carbon signals, of which 29 were assigned to the aglycon moiety and 11 were assigned to the sugar moiety (Tables $1-3$ ). The ${ }^{1} \mathrm{H}$ - and ${ }^{13} \mathrm{C}-\mathrm{NMR}$ spectra showed two anomeric proton signals at $\delta 4.92[\mathrm{~d}, J=7.8 \mathrm{~Hz}$, glucose (Glc)] and 5.27 [d, $J=6.9 \mathrm{~Hz}$, xylose (Xyl)] and two anomeric carbon signals at $\delta 105.0$ and 107.0, respectively. The six $s p^{3}$ hybrid carbons at $\delta 15.5,16.5,17.4,25.7,26.1$ and 27.9, and $s p^{2}$ hybrid carbons at $\delta 122.7(\mathrm{~d})$ and $144.4(\mathrm{~s})$, together with information from the ${ }^{1} \mathrm{H}-\mathrm{NMR}$ spectrum (six methyl proton singlets and a broad triplet olefinic proton at $\delta$ $5.54)$, indicated that the aglycon had an olean-12-ene skeleton. ${ }^{3)}$ Detailed analysis of various two-dimensional (2D) NMR spectra such as double-quantum filtered ${ }^{1} \mathrm{H}-{ }^{1} \mathrm{H}$ shift

correlation spectroscopy (DQF-COSY), heteronuclear multiple quantum coherence (HMQC), heteronuclear multiple bond correlation (HMBC) and phase-sensitive nuclear Overhauser enhancement spectroscopy (NOESY) spectra indicated that the structural features in the A, B, C and D rings of the aglycon were similar to those of oleanolic acid. ${ }^{4)}$ However, direct bond and long-range correlation data suggested that one of the geminal methyl groups at C-20 had been replaced by a hydroxyl group, forming 29-noroleanolic acid. In the NOESY spectrum (Fig. 1), H-18 was correlated with the methyl group at C-20, indicating that the hydroxyl group was in an $\alpha$-configuration. These results suggested that the aglycon of 1 was $3 \beta, 20 \alpha$-dihydroxy-29-norolean-12-en-28-oic acid. A related compound, 3 $\beta, 20 \xi$-dihydroxy-30(or 29)-

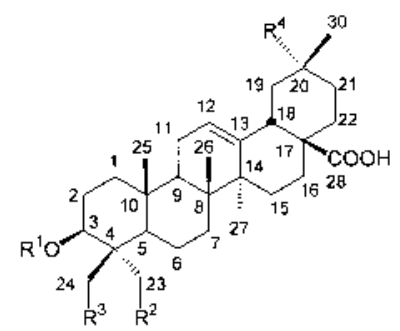

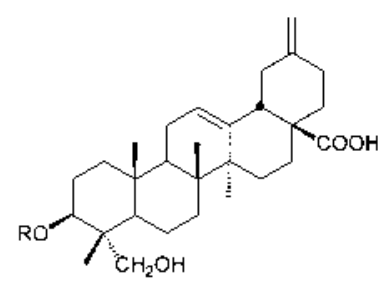

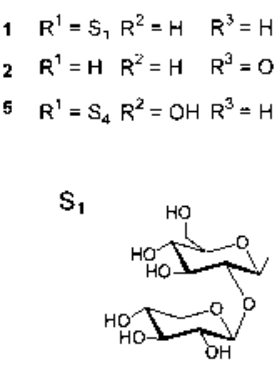

$$
\begin{array}{ll}
3 & R=s_{3} \\
4 & R=s_{4}
\end{array}
$$

$S_{3}$

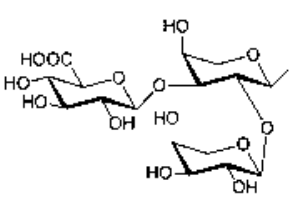

$3_{2}$

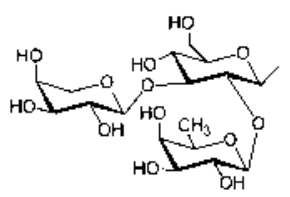

$s_{4}$

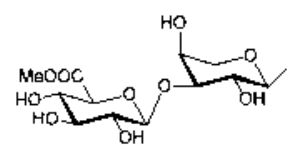


Table 1. ${ }^{13} \mathrm{C}-\mathrm{NMR}$ Data for the Aglycon Moieties of Fargosides A-E $(\mathbf{1}-\mathbf{5})\left(125 \mathrm{MHz}\right.$, Pyridine- $\left.d_{5}\right)$

\begin{tabular}{rrrrrr}
\hline \hline Carbon & \multicolumn{1}{c}{$\mathbf{1}$} & $\mathbf{2}$ & $\mathbf{3}$ & $\mathbf{4}$ & $\mathbf{5}$ \\
\hline 1 & 38.8 & 38.8 & 38.9 & 38.9 & 38.9 \\
2 & 26.7 & 28.1 & 26.0 & 26.3 & 26.3 \\
3 & 89.1 & 79.9 & 82.1 & 81.8 & 81.8 \\
4 & 39.6 & 42.7 & 43.7 & 43.6 & 43.6 \\
5 & 55.9 & 56.6 & 47.9 & 47.5 & 47.6 \\
6 & 18.5 & 19.0 & 18.2 & 18.1 & 18.2 \\
7 & 33.2 & 33.5 & 32.9 & 32.9 & 32.9 \\
8 & 39.8 & 39.7 & 39.8 & 39.8 & 39.8 \\
9 & 48.0 & 48.0 & 48.0 & 48.1 & 48.2 \\
10 & 37.0 & 37.1 & 36.9 & 36.9 & 37.0 \\
11 & 23.9 & 23.8 & 23.8 & 23.8 & 23.7 \\
12 & 122.7 & 122.5 & 123.1 & 123.1 & 122.6 \\
13 & 144.4 & 144.3 & 144.2 & 144.1 & 144.8 \\
14 & 42.2 & 42.1 & 42.1 & 42.1 & 42.2 \\
15 & 28.3 & 28.3 & 28.3 & 28.3 & 28.4 \\
16 & 23.8 & 24.0 & 23.8 & 23.8 & 23.9 \\
17 & 46.8 & 46.8 & 47.0 & 47.0 & 46.7 \\
18 & 44.4 & 44.4 & 48.1 & 47.9 & 42.0 \\
19 & 48.1 & 48.1 & 42.0 & 41.9 & 46.4 \\
20 & 69.9 & 69.9 & 149.1 & 149.1 & 31.0 \\
21 & 36.2 & 36.2 & 30.4 & 30.4 & 34.2 \\
22 & 35.2 & 35.1 & 38.4 & 38.4 & 33.3 \\
23 & 27.9 & 23.3 & 64.2 & 64.2 & 64.2 \\
24 & 16.5 & 73.2 & 13.5 & 13.7 & 13.7 \\
25 & 15.5 & 15.9 & 16.1 & 16.1 & 16.1 \\
26 & 17.4 & 17.3 & 17.4 & 17.4 & 17.5 \\
27 & 26.1 & 25.9 & 26.2 & 26.2 & 26.2 \\
28 & 180.0 & 179.9 & 179.4 & 179.4 & 180.2 \\
29 & & & 107.1 & 107.1 & 33.3 \\
30 & 25.7 & 25.7 & & & 23.8 \\
\hline & & & & &
\end{tabular}

Table 2. ${ }^{13} \mathrm{C}-\mathrm{NMR}$ Data for the Sugar Moieties of Fargosides A-E (15) $\left(125 \mathrm{MHz}\right.$, Pyridine- $\left.d_{5}\right)$

\begin{tabular}{|c|c|c|c|c|c|}
\hline Carbon & 1 & 2 & 3 & 4 & 5 \\
\hline & Glc & Glc & Ara (inner) & Ara & Ara \\
\hline 1 & 105.0 & 103.5 & 104.5 & 106.7 & 106.7 \\
\hline 2 & 84.0 & 77.3 & 77.6 & 72.1 & 72.1 \\
\hline 3 & 78.5 & 87.0 & 83.8 & 84.1 & 84.1 \\
\hline 4 & 71.7 & 69.5 & 69.1 & 69.4 & 69.4 \\
\hline 5 & 78.1 & 78.4 & 66.4 & 67.3 & 67.3 \\
\hline \multirow[t]{2}{*}{6} & 62.9 & 62.2 & & & \\
\hline & Xyl & Fuc & GlcA & MeGlcA & MeGlcA \\
\hline $1^{\prime}$ & 107.0 & 103.2 & 105.4 & 106.8 & 106.8 \\
\hline $2^{\prime}$ & 76.6 & 73.5 & 75.1 & 75.4 & 75.4 \\
\hline $3^{\prime}$ & 78.2 & 76.0 & 77.8 & 77.6 & 77.6 \\
\hline $4^{\prime}$ & 71.1 & 73.5 & 73.4 & 73.2 & 73.2 \\
\hline $5^{\prime}$ & 67.6 & 71.2 & 77.6 & 77.4 & 77.4 \\
\hline $6^{\prime}$ & & 17.1 & 172.7 & 170.6 & 170.6 \\
\hline \multirow{2}{*}{\multicolumn{2}{|c|}{$\mathrm{OCH}_{3}$}} & & & 52.1 & 52.1 \\
\hline & & Ara & Ara (terminal) & & \\
\hline $1^{\prime \prime}$ & & 105.5 & 105.0 & & \\
\hline $2^{\prime \prime}$ & & 73.0 & 73.6 & & \\
\hline $3^{\prime \prime}$ & & 74.8 & 75.1 & & \\
\hline $4^{\prime \prime}$ & & 69.7 & 69.8 & & \\
\hline $5^{\prime \prime}$ & & 67.8 & 67.2 & & \\
\hline $6^{\prime \prime}$ & & & & & \\
\hline
\end{tabular}

norolean-12-en-28-oic acid has been isolated from Guaiacum officinale. ${ }^{5)}$

Acid hydrolysis of $1 \mathrm{~m}$ hydrochloric acid in dioxane-water (1:1) gave D-glucose and D-xylose as the carbohydrate components. The monosaccharides, including their configura-
Table 3. ${ }^{1} \mathrm{H}-\mathrm{NMR}$ Data for Fargosides A-E (1-5) $(500 \mathrm{MHz}$, Pyridine$\left.d_{5}\right)^{a)}$

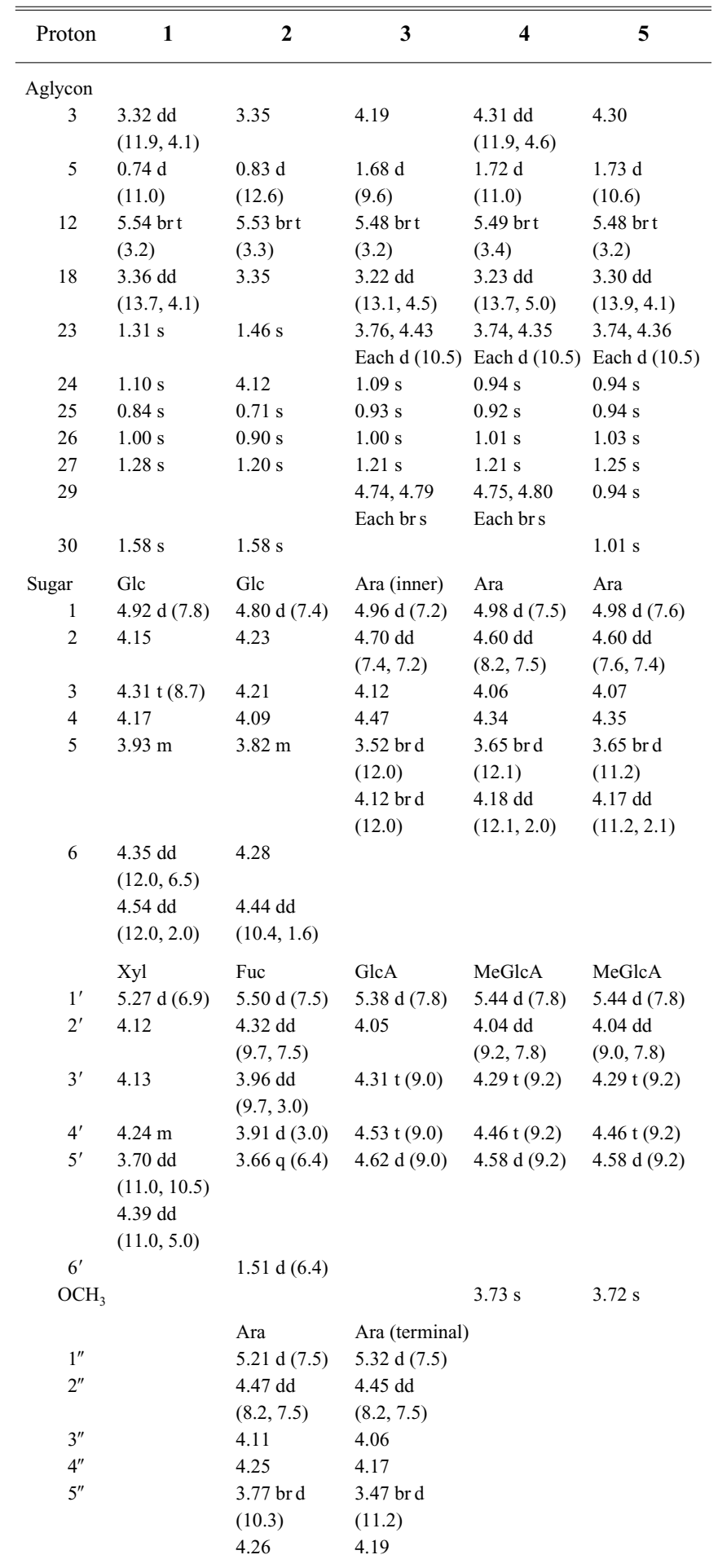

a) $J$ values (in $\mathrm{Hz}$ ) are in parentheses. Overlapped signals are reported without designating multiplicity.

tions, were identified by HPLC analysis following their conversion to the 1-[(S)-N-acetyl- $\alpha$-methylbenzylamino $]-1-$ deoxy-alditol acetate derivatives. ${ }^{6,7)}$ The interglycosidic linkage and the position of the sugar moiety attached to the aglycon were determined unambiguously by HMBC spectrum. The correlation between $\mathrm{H}-1(\delta$ 5.27) of Xyl and $\mathrm{C}-2(\delta$ 84.0) of Glc indicated that Xyl was linked to C-2 of Glc. A significant long-range correlation between $\mathrm{H}-1(\delta$ 4.92) of 


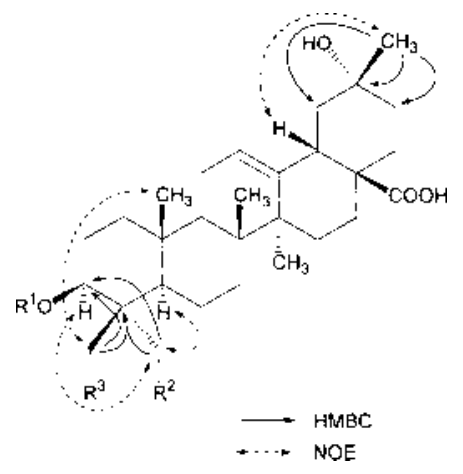

Fig. 1. Key HMBC and NOE Correlations Observed for $\mathbf{1}$ and $\mathbf{2}$

Glc and C-3 ( $\delta$ 89.1) of the aglycon indicated that Glc was linked to $\mathrm{C}-3$ of the aglycon. The ${ }^{13} \mathrm{C}-\mathrm{NMR}$ data indicated that both of the sugars were in the pyranose form. The $\beta$ anomeric configurations for glucose and xylose were determined from their large ${ }^{3} J_{\mathrm{H} 1, \mathrm{H} 2}$ coupling constants $(7-8 \mathrm{~Hz})$. Based upon all of the above evidence, the structure of fargoside $\mathrm{A}(\mathbf{1})$ was elucidated as $3 \beta, 20 \alpha$-dihydroxy-29-norolean12 -en-28-oic acid 3 - $O$ - $\beta$-D-xylopyranosyl-( $1 \rightarrow 2)-\beta$-D-glucopyranoside.

Fargoside B (2) gave quasi-molecular ions at $\mathrm{m} / \mathrm{z} 937$ $[\mathrm{M}+\mathrm{Na}]^{+}$and $953[\mathrm{M}+\mathrm{K}]^{+}$by MALDI-TOF MS. The molecular formula of $\mathrm{C}_{46} \mathrm{H}_{74} \mathrm{O}_{18}$ was confirmed by HR-FAB-MS. Comparison of the ${ }^{16} \mathrm{H}$ - and ${ }^{13} \mathrm{C}$-NMR spectra of 2 with those of 1 indicated one methyl group in $\mathbf{1}\left(\delta_{\mathrm{H}} 1.10\right.$ and $\left.\delta_{\mathrm{C}} 16.5\right)$ was replaced by a hydroxylmethyl group in $\mathbf{2}\left(\delta_{\mathrm{H}} 4.12\right.$ and $\left.\delta_{\mathrm{C}} 73.2\right)$. The ${ }^{13} \mathrm{C}-\mathrm{NMR}$ chemical shift of C-4 at $\delta_{\mathrm{C}} 42.7\left(\delta_{\mathrm{C}}\right.$ 39.6 in 1) indicated that the hydroxylmethyl group had replaced the 23- or $24-\mathrm{CH}_{3}$ group. The stereochemistry of the hydroxylmethyl group on $\mathrm{C}-4$ was assigned as $\beta$-configuration by a NOESY spectrum (Fig. 1). Therefore, the aglycon of 2 was identified as 3 $\beta, 20 \alpha, 24$-trihydroxy-29-norolean-12en-28-oic acid, a new triterpenoid sapogenin. The presence of three sugar units was indicated from the ${ }^{1} \mathrm{H}$ - and ${ }^{13} \mathrm{C}-\mathrm{NMR}$ data, which showed three sugar anomeric protons at $\delta 4.80$ $(\mathrm{d}, J=7.4 \mathrm{~Hz}), 5.21(\mathrm{~d}, J=7.5 \mathrm{~Hz})$, and $5.50(\mathrm{~d}, J=7.5 \mathrm{~Hz})$, and three anomeric carbons at $\delta 103.2,103.5$ and 105.5, respectively. The identity and sequence of the sugars were established using the same protocol as described for $\mathbf{1}$. The three monosaccharide units were identified as $\beta$-D-glucose (Glc), $\alpha$-D-arabinose (Ara) and $\beta$-D-fucose (Fuc), and further confirmed by HPLC analysis of the acid hydrolysate. The linkages of the sugar units at C-24 were established from the following HMBC correlations: H-1 of Fuc with C-2 of Glc and $\mathrm{H}-1$ of Ara with $\mathrm{C}-3$ of Glc. The attachment of the oligosaccharide moiety to C-24 of the aglycon was confirmed by a long-range correlation between $\mathrm{H}-1$ of Glc with $\mathrm{C}-23$ of the aglycon. Thus, the structure of fargoside B (2) was established as $3 \beta, 20 \alpha, 24$-trihydroxy-29-norolean-12-en28 -oic acid 23- $O$ - $\beta$-D-fucopyranosyl-( $(1 \rightarrow 2)$-[ $\alpha$-L-arabinopy-

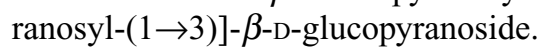

Fargoside C (3) gave quasi-molecular ions at $\mathrm{m} / \mathrm{z} 919$ $[\mathrm{M}+\mathrm{Na}]^{+}$and $935[\mathrm{M}+\mathrm{K}]^{+}$by MALDI-TOF MS. The molecular formula of $\mathrm{C}_{45} \mathrm{H}_{68} \mathrm{O}_{18}$ was confirmed by HR-FAB-MS. ${ }^{1} \mathrm{H}$-NMR spectrum showed four methyl proton singlets at $\delta$ $0.93,1.00,1.09$, and 1.21 , a broad triplet olefinic proton at $\delta$ 5.48 , and two exo-methylene protons at $\delta 4.74$ (s) and 4.79 (s). The ${ }^{13} \mathrm{C}$-NMR spectrum showed four tertiary methyl carbon signals at $\delta 13.5,16.1,17.4$, and 26.2, and four olefinic carbons at $\delta 107.1,123.1,144.2$, and 149.1. After extensive NMR analysis, the aglycon was characterized as $3 \beta, 23$-dihydroxy-30-norolean-12,20(29)-dien-28-oic acid (30-norhederagenin). ${ }^{8}$ Among the 45 carbon signals in the ${ }^{13} \mathrm{C}-\mathrm{NMR}$ spectrum, 29 were assigned to the aglycon (see Table 1). The remaining 16 signals were indicative of the presence of one hexose and two pentoses, in agreement with the three anomeric signals at $\delta 4.96(\mathrm{~d}, J=7.2 \mathrm{~Hz}), 5.32(\mathrm{~d}, J=7.5 \mathrm{~Hz})$, and $5.38(\mathrm{~d}, J=7.8 \mathrm{~Hz})$ in the ${ }^{1} \mathrm{H}-\mathrm{NMR}$ spectrum and the three anomeric carbon signals at $\delta 104.5,105.0$, and 105.4 in the ${ }^{13} \mathrm{C}$-NMR spectrum. Individual monosaccharides were identified by the $2 \mathrm{D}$ experiments. Three sugar units were identified as one glucuronic acid (GlcA) and two arabinoses (Ara), as further confirmed by GLC and TLC analysis of the acidic hydrolysate. The linkages of the sugar units were established from the following HMBC correlations: H-1 of the terminal Ara with C-2 of the inner Ara; H-1 of GlcA with C3 of the inner Ara; and the attachment of the oligosaccharide moiety to the aglycon was confirmed by a long-range correlation between $\mathrm{H}-1$ of the inner Ara with $\mathrm{C}-3$ of the aglycon. The $\alpha$-anomeric configurations for arabinoses and $\beta$ anomeric configuration for glucuronic acid were evident from their ${ }^{3} J_{\mathrm{H} 1, \mathrm{H} 2}$ coupling constants $(7-8 \mathrm{~Hz})$ and from NOE information. Based on these results, the structure of fargoside C (3) was established as 3 $\beta, 23$-dihydroxy-30norolean-2,20(29)-dien-28-oic acid 3-O- $\alpha$-L-arabinopyranosyl- $(1 \rightarrow 2)-[\beta$-D-glucopyranosyluronic acid $(1 \rightarrow 3)]-\alpha$-Larabinopyranoside.

Fargoside D (4) gave quasi-molecular ions at $\mathrm{m} / \mathrm{z} 801$ $[\mathrm{M}+\mathrm{Na}]^{+}$and $817[\mathrm{M}+\mathrm{K}]^{+}$by MALDI-TOF MS. The molecular formula of $\mathrm{C}_{41} \mathrm{H}_{62} \mathrm{O}_{14}$ was confirmed by HR-FAB-MS. The ${ }^{1} \mathrm{H}$ - and ${ }^{13} \mathrm{C}-\mathrm{NMR}$ data indicated that the aglycon of 4 was the same as that of $\mathbf{3}$, but that the two compounds have different sugar units. The ${ }^{1} \mathrm{H}$ - and ${ }^{13} \mathrm{C}-\mathrm{NMR}$ spectra showed two anomeric proton signals at $\delta 4.98(\mathrm{~d}, J=7.5 \mathrm{~Hz}$, Ara) and $5.44(\mathrm{~d}, J=7.8 \mathrm{~Hz}, \mathrm{GlcA})$ and two anomeric carbon signals at $\delta 106.7$ and 106.8 . The structure of the sugar moieties was determined by a combination of the 2D NMR experiments. The linkages of the sugar units were established by HMBC correlations observed between $\mathrm{H}-1$ of GlcA with C-3 of Ara, while the position of the disaccharide chain relative to $\mathrm{C}-3$ of the aglycon was based on a HMBC correlation between H-1 of Ara and C-3 of the aglycon. In addition, the resonance at $\delta$ $170.6(\mathrm{C}-6, \mathrm{GlcA})$ correlated with $\delta 3.73\left(3 \mathrm{H}, \mathrm{s}, \mathrm{OCH}_{3}\right)$ in the HMBC spectrum and indicated that the glucuronic acid unit was in the form of a methyl ester. Based on these results, the structure of fargoside $\mathrm{D}(\mathbf{4})$ was determined as $3 \beta, 23$-dihydroxy-30-norolean-12,20(29)-dien-28-oic acid 3-O-methyl $\beta$-D-glucopyranosyluronate-( $(1 \rightarrow 3)-\alpha$-L-arabinopyranoside.

Fargoside E (5) gave quasi-molecular ions at $\mathrm{m} / \mathrm{z} 817$ $[\mathrm{M}+\mathrm{Na}]^{+}$and $833[\mathrm{M}+\mathrm{K}]^{+}$by MALDI-TOF MS. The molecular formula of $\mathrm{C}_{42} \mathrm{H}_{66} \mathrm{O}_{14}$ was confirmed by HR-FAB-MS. Its ${ }^{1} \mathrm{H}$ - and ${ }^{13} \mathrm{C}-\mathrm{NMR}$ spectra indicated that $\mathbf{5}$ has the same sugar structure as that of $\mathbf{4}$, and the aglycon was identified as hederagenin. ${ }^{9,10)}$ Based on the above information, the structure of fargoside E (5) was established as 3 $\beta, 23$-dihydroxyolean-12-en-28-oic acid 3-O-mehtyl $\beta$-D-glucopyranosyluronate- $(1 \rightarrow 3)-\alpha$-L-arabinopyranoside. 


\section{Experimental Section}

General Experimental Procedures Optical rotations were recorded on a JASCO DIP-370 digital polarimeter. IR spectra were recorded on a JASCO 300E FT-IR spectrophotometer. ${ }^{1} \mathrm{H}$ - and ${ }^{13} \mathrm{C}-\mathrm{NMR}$ were recorded using a JEOL ECP-500 FT-NMR spectrometer. Chemical shifts are expressed in $\delta$ values (ppm) with TMS as internal standard and the coupling constants are in Hz. MALDI-TOF MS was conducted using a PerSeptive Biosystems Voyager DE-STR mass spectrometer. HR-FAB-MS were determined on a Kratos CONCEPT mass spectrometer. Diaion HP-20 (Mitsubishi Chemical), silica gel 60 (Merck) and ODS (Chromatorex, 100-200 mesh, Fuji Silysia) were used for column chromatography. Preparative HPLC was performed using an ODS column (Senshu Pak, PEGASIL ODS, $10 \mathrm{~mm}$ i.d. $\times 250 \mathrm{~mm}$, detector $210 \mathrm{~nm}$ ). GLC was carried out on a Shimadzu GC-7A instrument with Silicone OV-17 column on Uniport HP $2 \%, 3 \mathrm{~mm}$ i.d. $\times 2.1 \mathrm{~m}$. Column temperature, initially $140^{\circ} \mathrm{C}$ for $16 \mathrm{~min}$ and rising $2^{\circ} \mathrm{C} / \mathrm{min}$ to a final $170{ }^{\circ} \mathrm{C}$; carrier gas $\mathrm{N}_{2}$, flow rate, $25 \mathrm{ml} / \mathrm{min}$.

Plant Material. Fresh roots of Holboellia fargesii were collected in Kunming, Yunnan Province, People's Republic of China in May 1999 and identified by Professor Wen-Cai Fang (Kunming Institute of Chinese Medicinal and Folk Herb Drugs). A voucher specimen (no. 9905) is deposited at the herbarium of Beijing University, Beijing, People's Republic of China.

Extraction and Isolation The finely cut roots $(4 \mathrm{~kg})$ were extracted with $95 \% \mathrm{EtOH}$ three times under reflux for $3 \mathrm{~h}$. The combined $\mathrm{EtOH}$ extracts were evaporated under reduced pressure to yield a brown residue ( $260 \mathrm{~g}$ ), suspended in $\mathrm{H}_{2} \mathrm{O}$, and then partitioned successively with EtOAc and $n-\mathrm{BuOH}$. The $n-\mathrm{BuOH}$-soluble fraction $(124 \mathrm{~g})$ was applied to a column of Diaion HP-20 $(3000 \mathrm{ml})$ and eluted with $30,50,70$, and $100 \% \mathrm{MeOH}$. The fractions eluted with $70 \% \mathrm{MeOH}$ were combined and repeatedly chromatographed over silica gel and ODS columns to give several saponin fractions. Further HPLC purification of the highly polar fraction $(60-70 \%$ $\mathrm{MeOH}-0.06 \%$ TFA in $\mathrm{H}_{2} \mathrm{O}, 1.0 \mathrm{ml} / \mathrm{min}$, UV detector, $\left.210 \mathrm{~nm}\right)$ gave 1 (22 $\mathrm{mg}), 2$ (78 mg), 3 (5 mg), 4 (5 mg), and 5 (4 mg), respectively.

Fargoside A (1): An amorphous solid; $[\alpha]_{\mathrm{D}}^{25}+24.4^{\circ}(c=1.0, \mathrm{MeOH})$; IR (KBr) $v_{\max } 3423,2925,1685,1466,1388,1202,1045 \mathrm{~cm}^{-1} ;{ }^{1} \mathrm{H}-$ and ${ }^{13} \mathrm{C}-$ NMR data, see Tables 1-3; MALDI-TOF MS (positive-ion mode) $m / z 775$ $[\mathrm{M}+\mathrm{Na}]^{+}, 791[\mathrm{M}+\mathrm{K}]^{+}$; HR-FAB-MS (negative-ion mode) $\mathrm{m} / z 751.4263$ $[\mathrm{M}-\mathrm{H}]^{-}$(Calcd for $\left.\mathrm{C}_{40} \mathrm{H}_{63} \mathrm{O}_{13}, 751.4269\right)$.

Acid Hydrolysis of 1 A solution of $1(10 \mathrm{mg})$ in $1 \mathrm{M} \mathrm{HCl}$ (dioxane- $\mathrm{H}_{2} \mathrm{O}$, $1: 1,5 \mathrm{ml}$ ) was heated at $90^{\circ} \mathrm{C}$ for $2 \mathrm{~h}$ under an $\mathrm{Ar}$ atmosphere. After dioxane was removed, and the solution was extracted with EtOAc $(1 \mathrm{ml} \times 3)$. The extract was washed with $\mathrm{H}_{2} \mathrm{O}$ and then concentrated to give a residue, which was purified by silica gel column chromatography to give an aglycon (1a, $3 \mathrm{mg}$ ). The aqueous layer was neutralized by passing through an ion-exchange resin (Amberlite MB-3, Organo, Tokyo, Japan) column, concentrated under reduced pressure to dryness, to give a sugar fraction. The sugar fraction $\left(3 \mathrm{mg}\right.$ ) was dissolved in $\mathrm{H}_{2} \mathrm{O}(1 \mathrm{ml})$, to which $(-)-\alpha$-methylbenzylamine $(7 \mathrm{mg})$ and $\mathrm{NaBH}_{3} \mathrm{CN}(10 \mathrm{mg})$ in $\mathrm{EtOH}(1 \mathrm{ml})$ were added. After being set aside at $40{ }^{\circ} \mathrm{C}$ for $4 \mathrm{~h}$ followed by addition of glacial HOAc $(0.2$ $\mathrm{ml})$ and evaporated to dryness, the reaction mixture was acetylated with $\mathrm{Ac}_{2} \mathrm{O}(0.3 \mathrm{ml})$ and pyridine $(0.3 \mathrm{ml})$ in the presence of 4-dimethylaminopyridine $(5 \mathrm{mg})$ catalyst at $40^{\circ} \mathrm{C}$ for $12 \mathrm{~h}$. The crude mixture was passed through a Sep-Pak $\mathrm{C}_{18}$ cartridge (Waters) with $\mathrm{H}_{2} \mathrm{O}-\mathrm{MeCN}(4: 1 ; 1: 1$, each $10 \mathrm{ml})$ mixtures as solvents. The $\mathrm{H}_{2} \mathrm{O}-\mathrm{MeCN}(1: 1)$ eluate was further passed through a Toyopak IC-SP M cartridge (Tosoh, Tokyo, Japan) with EtOH (10 $\mathrm{ml})$ to a give mixture of the $1-[(S)-N$-acetyl- $\alpha$-methylbenzylamino $]-1-d e-$ oxyalditol acetate derivatives of the monosacchrides, ${ }^{5,6}$ which was then analyzed by HPLC under following conditions: solvent, $\mathrm{MeCN}-\mathrm{H}_{2} \mathrm{O}(2: 3)$; flow rate, $0.8 \mathrm{ml} / \mathrm{min}$; detection, UV $230 \mathrm{~nm}$. The derivatives of $\mathrm{D}$-xylose and D-glucose were detected as follows: $t_{\mathrm{R}}(\mathrm{min}) 26.50$ (derivative of $\mathrm{D}$-xylose) and 39.38 (derivative of D-glucose).

Aglycon (1a): An amorphous solid; $[\alpha]_{\mathrm{D}}^{25}+57.0^{\circ}(c=0.2, \mathrm{MeOH})$; IR (KBr) $v_{\max } 3420,2931,1695,1461,1383,1117,1030 \mathrm{~cm}^{-1} ;{ }^{1} \mathrm{H}-\mathrm{NMR}$ (pyridine- $\left.d_{5}, 500 \mathrm{MHz}\right): \delta 5.58(1 \mathrm{H}$, br s, H-12), $3.46(1 \mathrm{H}, \mathrm{m}, \mathrm{H}-3), 3.39(1 \mathrm{H}, \mathrm{dd}$, $J=10.4 .3 .7 \mathrm{~Hz}, \mathrm{H}-18), 1.60$ (3H, s, H-30), 1.27 (6H, s, H-23), $1.26(3 \mathrm{H}, \mathrm{s}$, $\mathrm{H}-27), 1.04(6 \mathrm{H}, \mathrm{s}, \mathrm{H}-24,26), 0.91(3 \mathrm{H}, \mathrm{s}, \mathrm{H}-25) ;{ }^{13} \mathrm{C}-\mathrm{NMR}$ (pyridine- $d_{5}$, $500 \mathrm{MHz}$ ): $\delta 180.0$ (C28) 144.4 (C-13), 122.2 (C-12), 78.1 (C-3), 69.9 (C20), 55.8 (C-5), 48.2 (C-19), 48.1 (C-9), 46.8 (C-17), 44.5 (C-18), 42.2 (C4), 39.8 (C-14), 39.4 (C-8), 38.9 (C-1), 37.4 (C-10), 36.3 (C-21), 35.2 (C22), 33.3 (C-7), 28.8 (C-23), 28.4 (C-15), 28.1 (C-2), 26.1 (C-27), 25.7 (C30), 23.9 (C-16), 23.8 (C-11), 18.8 (C-6), 17.5 (C-26), 16.5 (C-24), 15.6 (C25); MALDI-TOF MS (positive-ion mode) $m / z 481[\mathrm{M}+\mathrm{Na}]^{+}, 497[\mathrm{M}+\mathrm{K}]^{+}$.

Fargoside B (2): an amorphous solid; $[\alpha]_{\mathrm{D}}^{22}+39.6^{\circ}(c=1.0, \mathrm{MeOH}) ; \mathrm{IR}$ $(\mathrm{KBr}) v_{\max } 3414,2930,1689,1459,1380,1165,1061 \mathrm{~cm}^{-1} ;{ }^{1} \mathrm{H}-$ and ${ }^{13} \mathrm{C}-$
NMR data, see Tables 1-3; MALDI-TOF MS (positive-ion mode) $m / z 937$ $[\mathrm{M}+\mathrm{Na}]^{+}, 953[\mathrm{M}+\mathrm{K}]^{+}$; HRFABMS (negative-ion mode) $\mathrm{m} / \mathrm{z} 913.4787$ $[\mathrm{M}-\mathrm{H}]^{-}$(Calcd for $\left.\mathrm{C}_{46} \mathrm{H}_{73} \mathrm{O}_{18}, 913.4797\right)$.

Acid Hydrolysis of 2 Compound 2 (10 mg) was subjected to acid hydrolysis with $1 \mathrm{M} \mathrm{HCl}$ (dioxane- $\mathrm{H}_{2} \mathrm{O}, 1: 1,5 \mathrm{ml}$ ) at $90^{\circ} \mathrm{C}$ for $2 \mathrm{~h}$ under an $\mathrm{Ar}$ atmosphere, and workup similar to that of 1 gave a sugar fraction and an aglycon fraction. The monosacchrides in the sugar fraction were converted to the corresponding 1-[(S)- $N$-acetyl- $\alpha$-methylbenzylamino]-1-deoxyalditol acetate derivatives, which were then analyzed by HPLC. The derivatives of L-arabinose, D-fucose, and D-glucose were detected: $t_{\mathrm{R}}(\min ) 25.06$ (derivative of $\mathrm{L}$-arabinose), 32.49 (derivative of $\mathrm{D}$-fucose), and 39.18 (derivative of D-glucose). The aglycon fraction was purified by silica gel column chromatography using $\mathrm{CHCl}_{3}-\mathrm{MeOH}(19: 1)$ to give the aglycon $\mathbf{2 a}$.

Aglycon (2a): An amorphous solid; $[\alpha]_{\mathrm{D}}^{25}+39.2^{\circ}(c=0.2, \mathrm{MeOH})$; IR $(\mathrm{KBr}) v_{\max } 3415,2937,1697,1428,1250,1038 \mathrm{~cm}^{-1}$; ${ }^{1} \mathrm{H}-\mathrm{NMR}$ (pyridine$\left.d_{5}, 500 \mathrm{MHz}\right): \delta 5.57$ (1H, br s, H-12), $4.50(1 \mathrm{H}, \mathrm{d}, J=10.8 \mathrm{~Hz}, \mathrm{H}-23), 3.65$ (1H, m, H-3, overlapped with H-23), 3.64 (1H, H-23, overlapped with $\mathrm{H}-3)$, 3.38 (1H, dd, $J=13.6,5.5 \mathrm{~Hz}, \mathrm{H}-18), 1.60$ (3H, s, H-30), 1.56 (3H, s, H-24), 1.26 (3H, s, H-27), 0.99 (3H, s, H-26), 0.86 (3H, s, H-25); ${ }^{13} \mathrm{C}-\mathrm{NMR}$ (pyridine- $\left.d_{5}, 125 \mathrm{MHz}\right): \delta 180.7(\mathrm{C} 28), 144.4(\mathrm{C}-13), 122.6(\mathrm{C}-12), 80.2(\mathrm{C}-3)$, 69.9 (C-20), 64.5 (C-24), 56.4 (C-5), 48.2 (C-19), 48.1 (C-9), 46.8 (C-17), 44.4 (C-18), 43.2 (C-4), 42.1 (C-14), 39.8 (C-8), 38.7 (C-1), 37.1 (C-10), 36.3 (C-21), 35.2 (C-22), 33.6 (C-7), 28.4 (C-16), 28.3 (C-2), 26.0 (C-27), 25.7 (C-30), 24.0 (C-16), 23.9 (C-11), 23.6 (C-23), 19.1 (C-6), 17.3 (C-26), 16.0 (C-25); MALDI-TOF MS (positive-ion mode) $m / z 497[\mathrm{M}+\mathrm{Na}]^{+}$.

Fargoside $\mathrm{C}(3)$ : An amorphous solid; $[\alpha]_{\mathrm{D}}^{25}+54.0^{\circ}(c=0.6, \mathrm{MeOH})$; IR (KBr) $v_{\max } 3405,2929,1691,1443,1382,1171,1058 \mathrm{~cm}^{-1} ;{ }^{1} \mathrm{H}-$ and ${ }^{13} \mathrm{C}-$ NMR data, see Tables 1-3; MALDI-TOF MS (positive-ion mode) $\mathrm{m} / \mathrm{z} 919$ $[\mathrm{M}+\mathrm{Na}]^{+}, 935[\mathrm{M}+\mathrm{K}]^{+}$; HR-FAB-MS (negative-ion mode) $\mathrm{m} / z 895.4313$ $[\mathrm{M}-\mathrm{H}]^{-}$(Calcd for $\mathrm{C}_{45} \mathrm{H}_{67} \mathrm{O}_{18}, 895.4327$ ).

Fargoside D (4): An amorphous solid; $[\alpha]_{\mathrm{D}}^{23}+65.6^{\circ}(c=0.5, \mathrm{MeOH}) ; \mathrm{IR}$ $(\mathrm{KBr}) v_{\max } 3418,2936,1739,1689,1443,1383,1134,1057 \mathrm{~cm}^{-1} ;{ }^{1} \mathrm{H}-$ and ${ }^{13} \mathrm{C}$-NMR data, see Tables $1-3$; MALDI-TOF MS (positive ion mode) $\mathrm{m} / \mathrm{z}$ $801[\mathrm{M}+\mathrm{Na}]^{+}, 817[\mathrm{M}+\mathrm{K}]^{+}$; HR-FAB-MS (negative-ion mode) $\mathrm{m} / \mathrm{z}$ $777.4055[\mathrm{M}-\mathrm{H}]^{-}$(Calcd for $\left.\mathrm{C}_{41} \mathrm{H}_{61} \mathrm{O}_{14}, 777.4061\right)$.

Fargoside E (5): An amorphous solid; $[\alpha]_{\mathrm{D}}^{28}+18.3^{\circ}(c=0.8, \mathrm{MeOH})$; IR $(\mathrm{KBr}) v_{\max } 3397,2944,1739,1692,1444,1384,1136,1057 \mathrm{~cm}^{-1} ;{ }^{1} \mathrm{H}-$ and ${ }^{13} \mathrm{C}$-NMR data, see Tables $1-3$; MALDI-TOF MS (positive-ion mode) $\mathrm{m} / \mathrm{z}$ $817[\mathrm{M}+\mathrm{Na}]^{+}, 833[\mathrm{M}+\mathrm{K}]^{+}$; HR-FAB-MS (negative-ion mode) $\mathrm{m} / \mathrm{z}$ $793.4397[\mathrm{M}-\mathrm{H}]^{-}$(Calcd for $\mathrm{C}_{42} \mathrm{H}_{65} \mathrm{O}_{14}, 793.4374$ ).

Acid Hydrolysis of 3-5 A solution of compounds $3-\mathbf{5}$ (each $2 \mathrm{mg}$ ) in $1 \mathrm{ml}$ of $1 \mathrm{M} \mathrm{HCl}$ (dioxane- $\mathrm{H}_{2} \mathrm{O}, 1: 1$ ) was heated under reflux for $2 \mathrm{~h}$. After cooling, the reaction mixture was neutralized with by an ion-exchange resin (Amberlite MB-3) and resin was filtered. After removal of the solvent under reduced pressure, the residue was passed through a Sep-Pak $\mathrm{C}_{18}$ cartridge using $\mathrm{H}_{2} \mathrm{O}$ and $\mathrm{MeOH}$. The $\mathrm{H}_{2} \mathrm{O}$ eluate was analyzed by co-TLC to reveal the presence of glucuronic acid and arabinose with standard samples, then concentrated and the residue was treated with 1-trimethylsilylimidazole at room temperature for $1 \mathrm{~h}$. Excess reagent was then decomposed with $\mathrm{H}_{2} \mathrm{O}$, and the reaction product was extracted with $n$-hexane $(1 \mathrm{ml} \times 2)$. The TMSi derivatives of the monosaccharides were identified as arabinose $\left[t_{\mathrm{R}}(\mathrm{min})\right.$ 17.76 ( $\alpha$-anomer), 13.70 ( $\beta$-anomer), TMSi derivative of L-arabinose], by co-GLC analysis with standard monosaccharide.

\section{References}

1) Institutum Botanicum Kunmingense Academiae Sinicae (ed.), "Index Florae Yunnanensis," The People's Publishing House: Kunming, Yunnan, People's Republic of China, 1984, p. 148.

2) Yunnan Medicine Herbs Corporation, "Dictionary of Yunnan Medicinal Plants,” Kunming, Yunnan, People's Republic of China, 1989, p. 138 .

3) Mahato S., Kunda A. P., Phytochemistry, 37, 1517-1575 (1994).

4) Zhang Z., Koike K., Jia Z., Nikaido T., Guo D., Zheng J., Chem. Pharm. Bull., 47, 388-393 (1999).

5) Ahmad V. U., Bano N., Bano S., Phytochemistry, 23, 2613-2616 (1984).

6) Oshima R., Kumanotani J., Chem. Lett., 1981, 943-946.

7) Oshima R., Yamauchi Y., Kumanotani J., Carbohydr. Res., 107, 169176 (1982).

8) Ikuta A., Itokawa H., Phytochemistry, 28, 2663-2665 (1989).

9) Kojima K., Zhu X.-B., Ogihara Y., Phytochemistry, 48, 885-888 (1998).

10) Li H. Y., Koike K., Ohmoto T., Phytochemistry, 35, 751-756 (1994). 